\title{
The Best Nurturers in Computer Science Research
}

\author{
Bharath Kumar M. Y. N. Srikant
}

\author{
IISC-CSA-TR-2004-10 \\ http://archive.csa.iisc. ernet.in/TR/2004/10/ \\ Computer Science and Automation \\ Indian Institute of Science, India \\ October 2004
}




\title{
The Best Nurturers in Computer Science Research
}

\author{
Bharath Kumar M.* $\quad$ Y. N. Srikant ${ }^{\dagger}$
}

\begin{abstract}
The paper presents a heuristic for mining nurturers in temporally organized collaboration networks: people who facilitate the growth and success of the young ones. Specifically, this heuristic is applied to the computer science bibliographic data to find the best nurturers in computer science research. The measure of success is parameterized, and the paper demonstrates experiments and results with publication count and citations as success metrics. Rather than just the nurturer's success, the heuristic captures the influence he has had in the independent success of the relatively young in the network. These results can hence be a useful resource to graduate students and post-doctoral candidates. The heuristic is extended to accurately yield ranked nurturers inside a particular time period. Interestingly, there is a recognizable deviation between the rankings of the most successful researchers and the best nurturers, which although is obvious from a social perspective has not been statistically demonstrated.
\end{abstract}

\section{Keywords:}

Social Network Analysis, Bibliometrics, Temporal Data Mining.

\section{Introduction}

Consider a student Arjun, who has finished his under-graduate degree in Computer Science, and is seeking a $\mathrm{PhD}$ degree followed by a successful career in Computer Science research. How does he choose his research advisor? He has the following options with him:

1. Look up the rankings of various universities [1], and apply to any "reasonably good" professor in any of the top universities.

Does working with any reasonably good professor at a top university ensure that Arjun gets the training to pursue a successful research career?

\footnotetext{
*Author for TR correspondence. mbk@csa.iisc.ernet.in

†srikant@csa.iisc.ernet.in
} 
2. Look up the web sites that present the most successful researchers, based on the number of publications [2], the citations they have received [3] [4], or by their Erdos Number [5].

Arjun can then do his own analysis and find out how many of these researchers are active at the current date. He wants to ensure he does not work with a professor who's past his prime; or neglect a young and upcoming professor.

But still, does working with a top professor, who's known for his research, imply Arjun will learn how to do good research and in due course have a successful research career?

3. Get word-of-mouth information on the social aspects of working with a particular advisor.

Arjun can talk to an advisor's past and current students, get their feedback, attribute a certain trust to what each one says, and then decide.

How many people will Arjun ask? How much will he trust each individual feedback?

For Arjun, it is more important to seek a professor who will nurture him to become a good researcher: one who will teach him how best to do research that ends up in good publications, one who will bootstrap him into a good research network, where he hops onto a successful research career path on his own. Although being with a good researcher or in a top school does help, there is no guarantee of being nurtured. A good researcher may not be a good nurturer, and getting into a top school does not always ensure a good research career.

Arjun would benefit if:

- there is a way to summarize the nurturing ability of a researcher by mining the performance of people he nurtured, and thereby compare one nurturer with another.

- there is a way to find out the best nurturers in a given period of time.

- there is a way to find out researchers who have nurtured people,

- to publish many papers.

- to obtain many citations for their papers.

- in a given area of research. 
This paper presents a Nurturer-Finder heuristic that Arjun can use. When Arjun chooses to work with any of these people, he is assured that he is not just choosing them for their research prowess, but for the positive experiences people like himself had in the past. It may turn out that the nurturers also happen to be successful researchers themselves, as the results show.

The table 1 shows the output of the Nurturer-Finder heuristic; the top 50 authors based on publication count (every publication gets the author

a value of $\frac{1}{\text { number of authors }}$ ), and the top 50 nurturers computed on the Computer Science bibliographic database DBLP [2].

\section{The Nurturer-Finder's Design Principles}

While it may be argued that nurturing may even happen inside the confines of a classroom, or even through well-written books, mining among associations in bibliographic databases remains the best context to look for nurturers in research:

- Publishing is the defacto standard for evaluating good research.

- The art of scientific reporting is best taught "hands on". Senior collaborators typically give direction on the most important aspects of the innovation, provide appropriate feedback on its capabilities and limitations, and contrast the innovation with other progress in the area.

- People who have contributed towards a research project often end up as co-authors in the subsequent publication.

- Bibliographic databases are well documented, and are already used for extensive analysis of the impact of research.

However, all publications may not have a nurturer-nurtured pair; often, publications have "almost equals" as co-authors. Hence, the heuristic must not stray in its analysis, and report any co-author pair as a nurturer-nurtured pair. In contrast, no co-author pair can be neglected, since every collaboration can potentially be a context of nurturing.

The nurturer-finder heuristic is inspired by the concept of gurudakshina known from ancient Indian traditions. After finishing his education, a student (shishya) pays tribute to his teacher (guru) for the knowledge he was bestowed. On the same light, whenever a person achieves some success 


\begin{tabular}{|c|c|c|c|c|}
\hline \multirow[t]{2}{*}{ Rank } & \multicolumn{2}{|l|}{ Top Authors } & \multicolumn{2}{|l|}{ Top Nurturers: Publication Count } \\
\hline & Name & Value & Name & Value \\
\hline 1 & Bill Hancock & 161.00 & Jeffrey D. Ullman & 144.39 \\
\hline 2 & Joseph Y. Halpern & 143.23 & Zohar Manna & 126.91 \\
\hline 3 & Diane Crawford & 137.00 & Albert R. Meyer & 113.88 \\
\hline 4 & Grzegorz Rozenberg & 135.27 & Michael Stonebraker & 106.20 \\
\hline 5 & Moshe Y. Vardi & 135.00 & John E. Hopcroft & 97.23 \\
\hline 6 & Kang G. Shin & 131.57 & Robert Endre Tarjan & 95.72 \\
\hline 7 & Micha Sharir & 131.20 & Ugo Montanari & 90.14 \\
\hline 8 & Christos H. Papadimitriou & 129.39 & C. V. Ramamoorthy & 88.30 \\
\hline 9 & Hermann A. Maurer & 125.08 & Zvi Galil & 83.51 \\
\hline 10 & Philip S. Yu & 117.71 & Christos H. Papadimitriou & 81.95 \\
\hline 11 & Ronald R. Yager & 116.95 & Ronald L. Rivest & 80.45 \\
\hline 12 & Hector Garcia-Molina & 114.12 & Kurt Mehlhorn & 78.20 \\
\hline 13 & Jeffrey D. Ullman & 111.37 & John Mylopoulos & 77.01 \\
\hline 14 & Kurt Mehlhorn & 110.60 & Amir Pnueli & 76.27 \\
\hline 15 & Michael Stonebraker & 110.48 & Grzegorz Rozenberg & 75.86 \\
\hline 16 & David Eppstein & 110.01 & Richard J. Lipton & 75.00 \\
\hline 17 & Sudhakar M. Reddy & 105.16 & John H. Reif & 74.42 \\
\hline 18 & Arto Salomaa & 103.77 & Adi Shamir & 74.26 \\
\hline 19 & Saharon Shelah & 102.67 & Jacob A. Abraham & 73.51 \\
\hline 20 & Manfred Broy & 101.22 & Leonidas J. Guibas & 71.76 \\
\hline 21 & John H. Reif & 99.92 & Oscar H. Ibarra & 69.56 \\
\hline 22 & Elisa Bertino & 98.94 & Jan van Leeuwen & 69.37 \\
\hline 23 & Richard T. Snodgrass & 98.54 & Micha Sharir & 69.26 \\
\hline 24 & Oded Goldreich & 98.15 & Shimon Even & 68.78 \\
\hline 25 & David B. Lomet & 97.34 & Gio Wiederhold & 68.09 \\
\hline 26 & Robert Endre Tarjan & 96.71 & Kang G. Shin & 67.42 \\
\hline 27 & Gerard Salton & 96.69 & Ashok K. Agrawala & 66.63 \\
\hline 28 & Oscar H. Ibarra & 94.98 & Edmund M. Clarke & 66.28 \\
\hline 29 & Peter G. Neumann & 94.66 & Avi Wigderson & 66.06 \\
\hline 30 & Gheorghe Paun & 94.32 & Franco P. Preparata & 66.05 \\
\hline 31 & Edwin R. Hancock & 93.12 & Richard C. T. Lee & 65.55 \\
\hline 32 & Christoph Meinel & 92.49 & Danny Dolev & 65.12 \\
\hline 33 & Bruno Courcelle & 92.00 & Alberto L. Sangiovanni-Vincentelli & 62.39 \\
\hline 34 & Derick Wood & 91.23 & Abraham Silberschatz & 61.91 \\
\hline 35 & Hartmut Ehrig & 89.03 & Catriel Beeri & 60.95 \\
\hline 36 & Ben Shneiderman & 88.92 & David J. DeWitt & 60.78 \\
\hline 37 & Bernard Chazelle & 88.22 & David P. Dobkin & 60.55 \\
\hline 38 & Marek Karpinski & 87.79 & Mike Paterson & 60.29 \\
\hline 39 & Won Kim & 87.53 & Clement T. Yu & 58.54 \\
\hline 40 & Ingo Wegener & 87.07 & Derick Wood & 57.52 \\
\hline 41 & Jeffrey Scott Vitter & 86.47 & Oded Goldreich & 56.94 \\
\hline 42 & Amir Pnueli & 86.13 & Hermann A. Maurer & 56.60 \\
\hline 43 & Ugo Montanari & 86.08 & Azriel Rosenfeld & 56.59 \\
\hline 44 & Robert L. Glass & 86.07 & Sartaj Sahni & 55.81 \\
\hline 45 & Nancy A. Lynch & 86.03 & Nancy A. Lynch & 54.98 \\
\hline 46 & Azriel Rosenfeld & 85.87 & Silvio Micali & 54.59 \\
\hline 47 & Sushil Jajodia & 84.40 & Theo Hrder & 54.53 \\
\hline 48 & Zvi Galil & 83.94 & Seymour Ginsburg & 54.34 \\
\hline 49 & David Harel & 83.91 & Stefano Ceri & 54.31 \\
\hline 50 & David Peleg & 83.26 & John L. Hennessy & 52.96 \\
\hline
\end{tabular}

\section{Table 1: Top 50 authors and nurturers based on publication count}

(through a publication), he attributes a part of that success to his "gurus" proportionate to their nurturing influence on him. The gurus with the highest gurudakshina are the best nurturers. 
The design principles are elucidated as follows:

1. The effect of nurturing manifests in the post-associative period.

Any amount of success a person may have with his nurturer, it is still not indicative whether he has been successfully nurtured. The nurturing is true and complete, when he tastes success "on his own" in the absence of his nurturer. This period is hence termed as post-associative, and is used as the context to decide the extent of the nurturing.

2. The more self-made a person is, the less he attributes his success to his past associates.

People who have seen success on their own, without associating with too many people, especially early in their career, can be termed as self-made. They are the self-motivated people, who probably were not nurtured at all by someone else. It is fair that these people attribute less of their success to their past associates.

3. The success achieved by a person at any time is considered to be influenced by all his past associates. However it is tributed to only those who do not have a direct pay-off in the current collaboration.

While contributing towards a publication, an author may be acting upon the influence he's had from many of his past and current associates. However, all the current associates (the co-authors) in the publication still have their own pay-offs from it. So, the tribute for one's success is only given away to past associates who have helped influence him to be successful in a current venture without a motive of their own.

4. The tribute is appropriated among the past associates in proportion to their estimated nurturing influence on the person.

Nurturing happens most when a person is still young in his career and the people who associated with him earlier are more important (in terms of a nurturing influence) than the ones he associates with later in his career. This can be termed as the strength of early association. As an aside - while the strength of early association of a person with his nurturer will be high, the reverse need not hold, since the nurturer is expected to be already relatively mature in his career.

A person need not have been nurtured equally by all people he had good early associations with. The ones who nurtured him more are most likely those who were termed to have a good nurturing ability by other people as well. 
Thus, an associate's nurturing influence on a person is proportional to the strength of early association with this person and the associate's own nurturing ability. The tribute can then be appropriated to each past associate in accordance to the proportion of their nurturing influence.

The above principles guide the design of the Nurturer-Finder heuristic, which works based on the following outline. Publications are processed in temporal sequence, at some granularity, either grouped by years or by months.

1. As every person publishes, his strength of early association with his associates, and their nurturing influence on him are tracked.

2. Every time he achieves a certain success from a publication, it is tributed to his past associates for influencing him in his "formative" years, in accordance to their nurturing influence. The more self-made a person is, the less is his tribute.

3. Every person collects the tribute he gets from others.

4. The person with the highest tribute is the best nurturer. People can also be sorted on the tributes they have, to arrange them in nonincreasing order of their nurturing abilities.

\section{The Formulation of the Nurturer-Finder Heuristic}

The heuristic is abstractly formulated, allowing for reuse in domains outside of bibliographic databases.

A publication is an instance of a collaboration, and happens at a certain discrete instant in time. The bibliographic database is termed as the set of collaborations.

- A collaboration $c$ has the following properties, associates $_{c}$, the set of people involved in the collaboration $c$.

time $_{c}$, the time at which the collaboration happened.

significance $_{c}$, the quantifier representing the significance of the collaboration, which could be equal to 1 , the impact factor of the conference or journal where it was published, or the number of citations the publication has received. 
- Each associate $p$ in a collaboration gets a certain significance measure to himself: his share of success. In the model used here, the success is equally shared among the associates.

$$
\text { significance }_{c}^{p}= \begin{cases}\frac{\text { significance }_{c}}{\mid \text { associates }_{c} \mid} & \text { if } p \in \text { associates }_{c} \\ 0 & \text { if } p \notin \text { associates }_{c}\end{cases}
$$

Other models, for instance, can give importance to the position of the author's name in the list, while deciding the significance of each associate.

- The set of all collaborations that have happened till time $t$, is given by,

$$
\text { collaborations }^{t}=\left\{c \in \text { collaborations } \mid \text { time }_{c}<t\right\}
$$

Note: The collaborations that happened at the time instant $t$ are not included in this set.

- The set of all people involved in all collaborations till time $t$ is represented by,

$$
\text { people }^{t}=\bigcup\left\{\text { associates }_{c}: c \in \text { collaborations }^{t}\right\}
$$

- The cumulative significance of each person until time $t$ is represented by,

$$
\text { cumulative-significance }_{p}^{t}=\sum_{c \in \text { collaborations }} \text { significance }_{c}^{p}
$$

- A measure of the degree of association a person $q$ had in the signifiance a person $p$ achieved during a collaboration $c$ is given by,

$$
{ }^{q} \text { association }_{p}^{c}=\text { significance }_{c}^{p} * \frac{\text { significance }_{c}^{q}}{\text { significance }_{c}}
$$

The $\frac{\text { significance }_{c}^{q}}{\text { significance }_{c}}$ factor is indicative of $q$ 's involvement in $c$. Higher $q$ 's involvement, higher is his association with $p$ 's significance.

- The early association $q$ had with $p$, until time $t$ is representative of the successful collaboration $p$ had with $q$ early in his career.

$$
{ }^{q} \text { early-association }_{p}^{t}=\sum_{c \in \text { collaborations }}^{t}\left(\frac{{ }^{q} \text { association }_{p}^{c}}{\text { cumulative-significance }_{p}^{\text {time }_{c}}}\right)
$$


- A measure of how self-made a person is, is also useful - to determine his independence on his associates for his success. This measure also considers the earliness of his self-establishment. The intuition being that, a person who gets independent success later in his career, but after collaborating with people early on, is not as self-made as a person who was independent right from the start. It is likely that a self-made person was not nurtured by too many people at all, and hence he must attribute less of his success to his 'mentors'.

$$
\text { self-establishment }{ }_{p}^{t}={ }^{p} \text { early-association }{ }_{p}^{t}
$$

- The nurturing-influence a person $q$ has had on $p$, (where $p \neq q)$ until time $t$ is given by

$$
\begin{gathered}
\sum_{c \in \text { collaborations }}{ }^{q} \text { nurturing-influence }{ }_{p}^{t}= \\
\left(\frac{{ }^{a} \text { association }_{p}^{c} *\left(\text { nurtureship }_{q}^{\text {time }_{c}}\right)^{\alpha}}{\text { cumulative-significance }_{p}^{\text {time }_{c}}}\right)
\end{gathered}
$$

The term nurtureship $p_{p}^{t}$ which is detailed later, is indicative of the nurturing ability of a person $p$ until time $t$.

Since nurtureship is collected based on tributes from other people, it has a tendency to grow faster than the cumulative significance of a person. The cumulative significance typically grows linearly since a person can only put a relatively constant amount of effort every year. The selection of $\alpha$ determines the domination nurtureship has over cumulative significance. For higher values of $\alpha$, a person with higher nurtureship imparts a bigger nurturing-influence, even if the person is well into his career. For smaller values of $\alpha$, the earliness factor dominates the nurturing influence. Increasing the value of $\alpha$ makes the people with higher nurtureship "richer" at the cost of the others. In the experiments reported in the paper, $\alpha$ was hand-engineered to 0.5 , for satisfactory results.

${ }^{p}$ nurturing-influence ${ }_{p}^{t}$ is not defined. A person does not nurture himself.

- The tribute given away to past associates everytime a person $p$ achieves a certain significance through a collaboration $c$, is given by

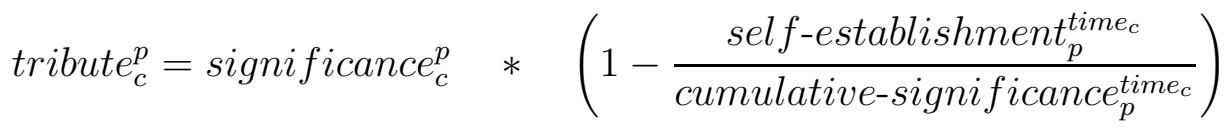


- The tribute a person $p$ gives to an associate $q$, (where $p \neq q$ ), because of achieving a certain significance through a collaboration $c$ is given by

$$
\begin{aligned}
& { }^{q} \text { tribute }{ }_{c}^{p}= \\
& \left\{\begin{array}{c}
\frac{\text { tribute }_{c}^{p} *{ }^{q} \text { nurturing-influence }_{p}^{\text {time }_{c}}}{\left.\sum_{r \in\left(\text { people }^{{ }_{\text {time }}} \text { nurturing-influence }_{p}^{\text {time }}{ }_{c}\right.}-p\right)} \\
\text { if } q \notin \text { associates }_{c} \\
\text { if } q \in \text { associates }_{c}
\end{array}\right.
\end{aligned}
$$

The tribute is thus appropriated proportionate to the nurturing influence.

- The nurtureship $p_{p}^{t}$ of a person is the cumulative sum of the tributes collected by $p$ from other associates until time $t$. The term nurtureship $p_{p}^{t^{\prime}}$ is used to represent the nurturing ability of a person right after time $t$, inclusive of the collaborations that happened in that time instant. This is incrementally calculated.

$$
\text { nurtureship }_{p}^{t^{\prime}}=\text { nurtureship }_{p}^{t}+\sum_{\substack{c \in \text { collaborations } ; \\ \text { time } \\ \text { timeassociates }_{c}}} \sum_{\text {tribute }}^{q}
$$

and

$$
\text { nurtureship } p_{p}^{0}=1
$$

Thus, the best nurturer is one who has the highest nurtureship $p_{p}^{t^{\prime}}$ where $t$ is the current time.

- The total tribute a person $p$ gives to an associate $q$ until time $t$ is represented by,

$$
{ }^{q} \text { tribute }_{p}^{t}=\sum_{c \in \text { collaborations }}{ }^{q} \text { tribute }_{c}^{p}
$$

This is used to present a drill down of the nurtureship of each person, showing the extent of tribute each of their nurtured give them. ${ }^{p}$ tribute $_{p}^{t}=1.0$ This accounts for the default value of nurtureship $p_{p}^{0}$. 


\section{Some Experiments on the DBLP Database}

The Digital Bibliography and Library Project (DBLP) [2] provides digital information on major computer science journals and publications, and indexes more than 520000 articles. Citations are also available for a subset of the articles indexed. The DBL-browser offers an interface to access the compressed database containing the article information. The Nurturer-Finder heuristic was applied on the DBLP in two sets of experiments with the significance measure for each publication being a constant, and the number of citations it received, respectively. Since the DBLP does not have a comprehensive list of all citations, the results based on citations are not as accurate as the other one, based on publication count.

The algorithm to implement the Nurturer-Finder heuristic used a few optimizations. Nurturing-influence is only tracked between a pair of people who have had an association already. This conserved the space and time needed during calculations. The intermediate values of tributes and nurturing-influences, for every year given by a person to another are stored, to facilitate calculating the nurturers over different time slices. Re-runs for different time slices can then give lists of nurturers without having to mine the whole database again. The algorithm was implemented using Java, and used the DBL Browser libraries [6] for accessing the publication records. The algorithm is incremental in nature, and parses each publication in the database exactly once. Every time a publication is processed, all past associates of every co-author are processed, to be assigned tributes.

$\alpha$ is chosen as 0.5 in the following experiments. A discussion on the choice of $\alpha$ is considered later in the paper.

\subsection{Nurturing for Publication Count}

The top 50 authors and the top 50 nurturers are reported based on publication count as the significance measure. Every entry in the DBLP has a significance of 1 , and an author's significance for participation is $\frac{1}{\mid \text { associates } \mid}$. Thus, people with the highest sum, based on the fraction of their participation in each publication, are reported as the top researchers. This metric in itself is not semantically very accurate due to the disparity in quality among the journals and conferences indexed by the DBLP, but still acts as a good measure to compare the results of the best authors with the best nurturers. Table 1 displays the top authors according to their cumulative fractional publication count, and the top nurturers according to the cumulative tributes they have got. Although the semantics of top authors and top nurturers 


\begin{tabular}{|c|c|c|}
\hline$\overline{R a n k}$ & $\begin{array}{l}\text { Nurturer } \\
\text { Nurtured }\end{array}$ & Value \\
\hline \multirow[t]{9}{*}{1} & Jeffrey D. Ullman & 144 \\
\hline & Henry F. Korth & 8 \\
\hline & Yehoshua Sagiv & 8 \\
\hline & Fereidoon Sadri & 7 \\
\hline & Alberto O. Mendelzon & 6 \\
\hline & Sam Toueg & 6 \\
\hline & Ravi Sethi & 5 \\
\hline & David Maier & 5 \\
\hline & Joan Feigenbaum & 5 \\
\hline \multirow[t]{10}{*}{2} & Zohar Manna & 126 \\
\hline & Martn Abadi & 23 \\
\hline & Amir Pnueli & 21 \\
\hline & Adi Shamir & 15 \\
\hline & Nachum Dershowitz & 11 \\
\hline & Shmuel Katz & 6 \\
\hline & Thomas A. Henzinger & 6 \\
\hline & Jean Vuillemin & 5 \\
\hline & Luca de Alfaro & 5 \\
\hline & Ashok K. Chandra & 5 \\
\hline \multirow[t]{5}{*}{3} & Albert R. Meyer & $\overline{113}$ \\
\hline & Joseph Y. Halpern & 38 \\
\hline & John C. Mitchell & 11 \\
\hline & Nancy A. Lynch & 7 \\
\hline & David Harel & 7 \\
\hline \multirow[t]{8}{*}{4} & Michael Stonebraker & 106 \\
\hline & Marti A. Hearst & 8 \\
\hline & Michael J. Carey & 7 \\
\hline & Akhil Kumar & 7 \\
\hline & Timos K. Sellis & 6 \\
\hline & Sunita Sarawagi & 5 \\
\hline & Joseph M. Hellerstein & 5 \\
\hline & Margo I. Seltzer & 5 \\
\hline \multirow[t]{7}{*}{5} & John E. Hopcroft & 97 \\
\hline & Jeffrey D. Ullman & 24 \\
\hline & Robert Endre Tarjan & 14 \\
\hline & Richard Cole & 12 \\
\hline & Steven Fortune & 5 \\
\hline & Joachim von zur Gathen & 5 \\
\hline & Gordon T. Wilfong & 5 \\
\hline \multirow[t]{6}{*}{6} & Robert Endre Tarjan & 95 \\
\hline & Thomas Lengauer & 11 \\
\hline & Haim Kaplan & 6 \\
\hline & Jeffery Westbrook & 6 \\
\hline & Andrew V. Goldberg & 6 \\
\hline & David R. Cheriton & 5 \\
\hline \multirow[t]{8}{*}{7} & Ugo Montanari & 90 \\
\hline & Roberto Gorrieri & 7 \\
\hline & Andrea Corradini & 7 \\
\hline & Francesca Rossi & 6 \\
\hline & Vladimiro Sassone & 6 \\
\hline & Alberto Martelli & 6 \\
\hline & Pierpaolo Degano & 5 \\
\hline & Giorgio Levi & 5 \\
\hline
\end{tabular}

Table 2: Publication Count: Top nurturers and their nurtured 
are very different, it is noticable that a few people in the top authors do not exist in the top nurturers table.

The tables 2 and 3 show the drill down for a few top nurturers. The drill down lists people who were 'nurtured' by them, and the value of the tributes they gave away to the nurturer. These nurtured people are those who co-authored with the nuturers early in their careers, and then went onto be prolific on their own as authors, even in the absence of their nurturers. Only people who gave away tributes greater than or equal to the value 5 are listed. A person may appear as "nurtured" by more than one nurturer, if he gave away reasonably big tributes to all of them.

\subsubsection{Interpreting the results}

- The heuristic attempts to recognize the social trait of nurturing through statistical analysis, and hence acceptance of the validity of the findings is possible only by common perception of readers conversant with the who's who of the computer science research community.

- While it is questionable whether there exists a strict nurturer-nurtured distinction in the results, if the border is blurred to mean a nurturing influence, which can be mutual too at times, the results become easier to digest.

- The list of nurturers, on its own, has successful researchers. The authors found this phenomenon most interesting because the calculation of nurtureship does not take into account any publication of the nurturer himself, and considers only post-associative success of people who co-authored with them early in their career.

- The results also suggest the ability of these people to sight talent: people who would later end up doing very well on their own. Good nurturers are also good talent sighters.

The figure 1 shows a few typical ways the nurtureship of different people has grown year by year. Assuming that the number of publications a person can yield over a year by and large remains a constant, a closer inspection of the curves reveals the following phases in growth:

1. Quadratic growth: A quadratic growth phase implies that during this period, the nurturer is collecting tributes from people he nurtured in the past, and also that he continues to nurture newer people. 


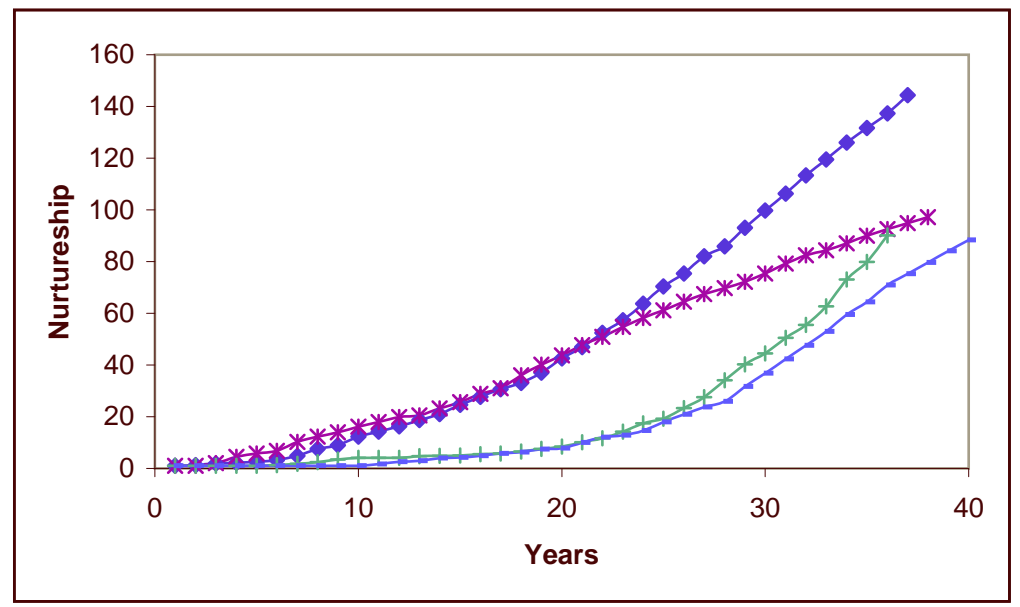

Figure 1: Some typical Nurtureship Growth curves

2. Linear growth: In a linear growth phase, the tributes he is receiving have evened out, and he receives a constant tribute each year. This happens if the number of people he has nurtured that are still actively publishing remains a constant, most likely since he has stopped nurturing newer people.

3. Negligible growth: The nurturer has stopped nurturing newer people, and the people he had nurtured in the past too have stopped publishing actively.

The figure 1 shows phases of both quadratic and linear growth in a few curves, with the linear growth normally occuring towards the latter stages. For these curves to level out, we may have to wait for a few more years when the second generation of computer science researchers stop being active. Signs of leveling out can be seen in at least one of the curves in the figure. A more formal study of the phases in each curve, a means to automatically identify the phase of nurtureship a person is in, will provide very useful information on how actively a person is still nurturing.

\subsection{Nurturing for Citations}

DBLP makes citations available for a subset of articles in the database. The database is pre-processed once and the number of times a particular article is cited, into the entire future available, is computed. Results of nurturers obtained based on citations is biased towards the earlier articles, since many of 
the recently published articles would not have reached their fullest "citation potential".

Using citations as the significance measure exposed a potential flaw in the heuristic. The number of citations an article receives can be huge, and thus, all its glory may be tributed to just any earlier associate. Some of these associates would get tributes from too few people, but large ones from those few people, which cast some doubts if they were "false positives". They typically cropped up quite often in cases where people's early research works received tremendous citations. This phenomenon was particularly not troublesome in the earlier significance measure, since each publication just had a significance of 1 , and to climb up the nurturer charts, a nurturer had to repeat his "nurturing" many times over with different people. However, with the case of citations, to have significantly high positions in the nurturer charts, it was enough to be associated early with just one person who ended up having lots of citations later. This phenomenon can be termed as tribute dominance (TD), where the total tribute obtained is heavily dominated by the tributes given by too few people. A measure of the tribute dominance is computed and used to weed out the false positives.

\subsubsection{Nurtureship Buffering based on Tribute Dominance}

A person's nurtureship is built based on contributions from several tributes, from different people. Given the nature of the heuristic, its not just the truly nurtured who pay tributes, but almost every associate gives a tribute, albeit in very small amounts. Using the mean across the tributes would be misleading, since a person may have got almost zero tributes from a lot of people, and yet be a good nurturer. Further, the variance will also dominated by the large number of small values in the distribution. A good measure to find the tribute dominance, should be invariant of the number of small values that make up the sum, and yet be able to find out if a particular nurtureship is dominated by too few tributes. A measure based on partial sums is used:

Consider, ${ }^{p}$ tribute $_{q}^{t}$ the total tribute $q$ has given to $p$ until time $t$, where ${ }^{p}$ tribute $e_{p}^{t}$ is made equal to 1.0, since the default value for nurtureship is 1.0.

The total tribute, the

$$
\text { nurtureship } p_{p}^{t}=\sum_{q \in \text { people }}{ }^{p} \text { tribute }_{q}^{t}
$$

Next, let ${ }^{p} T^{t}$ be an array of size $\mid$ people $e^{t}$, sorted in non-increasing order, with elements $\frac{{ }^{p} \text { tribute }_{q}^{t}}{\text { nurtureshipt }_{p}^{t}}$ for all $q \in$ people $e^{t}$. $T$ essentially contains the tributes of all people normalized by the total nurtureship, in sorted order. 
Next, let ${ }^{p} P S^{t}$ be an array made of partial sums of ${ }^{p} T^{t}$ such that,

$$
{ }^{p} P S_{i}^{t}=\sum_{j=i}^{\mid \text {people }{ }^{t} \mid}{ }^{p} T_{i}^{t} \quad \text { for } \quad i=1 \ldots \mid \text { people } e^{t} \mid
$$

The tribute dominance,

$$
{ }^{p} T D^{t}=\frac{1}{\sum_{i=1}^{\mid \text {people }}{ }^{t} p P S_{i}^{t}}
$$

For people, with a high tribute dominance, i.e. just a few people contributing to most of the nurtureship, ${ }^{p} T D^{t}$ converges on 1.0. For those with a good distribution among their tributes, i.e. comparable tributes coming from many sources, ${ }^{p} T D^{t}$ tends to be smaller. The upper bound on ${ }^{p} T D^{t}$ is 1 , and the lower bound is $\frac{2}{\left|p e o p l e^{t}\right|+1}$ (for the case where every person contributes an equal amount) which is relatively impractical. In these experiments, the lowest tribute dominance observed was 0.09.

Tributes to a person with high tribute dominance cannot be discarded right away. It may be the case that this person is just starting his tenure as a nurturer, and got successful in making a successful person for the first time. Such cases cannot be penalized although they may start off with a high tribute dominance. For this, tributes made to people with high tribute dominance, are stored in a "buffer", and when in due course more people give tributes to them, and the tribute dominance goes under an "acceptable" threshold, the buffered tributes are "matured". While a person's tribute is buffered, it is not made known to other people, and hence does not influence the proportioning of the tribute among different nurturers. i.e. The buffered tribute is not considered while calculating the nurturing influences on a person.

Empirically, 0.5 was chosen as a reasonable tribute dominance threshold in these experiments. Although tribute dominance is not a concern in the experiments dealing with publication count, they were used there too, to be safe.

Using the tribute buffering technique along with the calculation of tribute dominance, removed most false positives from the results, and admitted into the nurturer ranks, only those people who had nurtured at least a few people to reasonable amounts.

\subsubsection{The results based on citations}

Table 4 shows the top cited people, and the top nurturers for citations for a subset of publications in the DBLP. Again, as earlier, a few top cited authors 


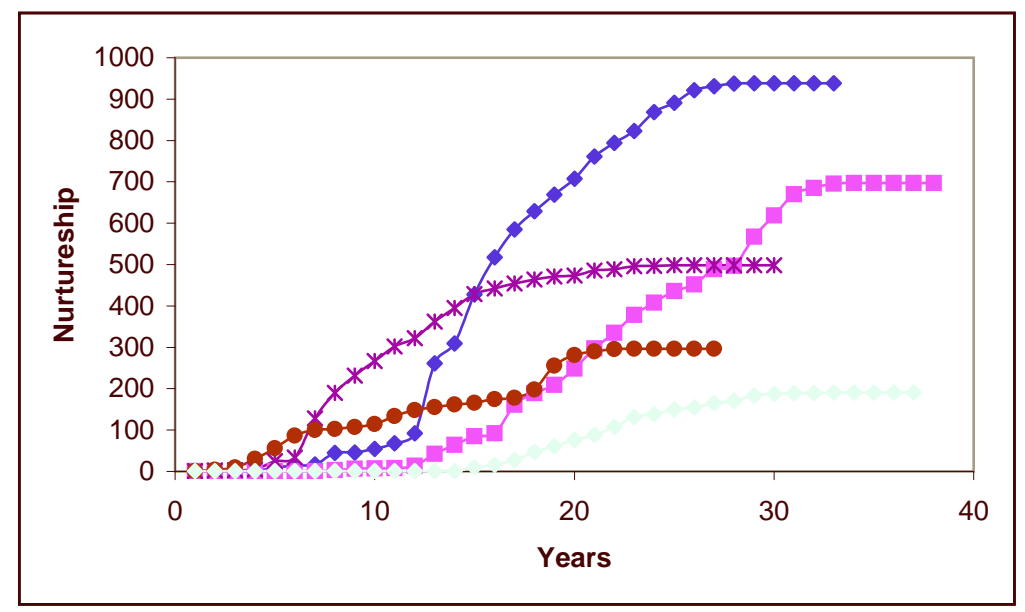

Figure 2: Some typical Nurtureship Growth curves for citations

do not have any presence in the list of top nurturers. The tables 5 and 6 show the drill down of the tributes of a few top nurturers showing the people who gave the highest tributes to each nurturer.

The figure 2 shows a few typical nurtureship growth curves. Unlike, the figure 1, no quadratic growth can be observed here, which indicates that nurturing new people to continually get highly cited is not easy, and it happens only once in a while. Most phases of growth tend to be linear, although with different slopes. The negligible growth seen towards the end are due to recent publications not yet reaching their fullest citation potential. People with extended phases of negligible growth can be considered not to be actively nurturing.

\section{The Best Nurturers in a Time Period}

Until now, the heuristic has been used to compute nurturers in the entire time period for which article information is available. Of interest to people, and especially students, is to find nurturers that are currently active and approachable. The heuristic in itself is biased towards the nurturers of earlier periods, since they get tributes from their nurtured for much longer periods in time. This causes a shadowing of the recent nurturers. Computing the best nurturers in smaller time periods does not boil down to using a subset of publications just pertaining to the time period - for the following reasons:

- If the computation starts at a time instant $t_{1}$, then all the past history of nurturers until then is lost. 
- Since his history has been wiped out, a bigger nurturer may get smaller shares of tributes, thus leading to a misappropriation of the tributes.

- The senior researchers themselves may end up giving substantial tributes to the younger ones.

Further, the nurtureship over a given time period cannot be calculated just by adding up the tributes given to a person in that time period. A person who has been nurtured by another, continues to give tributes to him throughout his career and hence these tributes may not be representative of the nurturing influence imparted during a particular time period.

Similarly, the nurtureship cannot consider only the new associations that were formed during that time period, since older associations may get nurtured too.

Hence, a measure of the nurturing influence imparted on a person in that time frame is used, and each tribute in that time period is added up proportionate to the nurturing influence a person received then.

$$
\begin{aligned}
& \text { nurtureship } p_{p}^{t_{1}-t_{2}}= \\
& \sum_{c \in \text { collaborations; }} \sum_{q \in \text { associates }_{c}} p_{\text {tribute }_{c}^{q}} * \\
& t_{1}<=\text { time }_{c}<=t_{2} \\
& \left(\frac{{ }^{p} \text { nurturing-influence }{ }_{q}^{t}-{ }^{p} \text { nurturing-influence }{ }_{q}^{t_{1}}}{{ }^{p} \text { nurturing-influence }{ }_{q}^{t}}\right)
\end{aligned}
$$

The tables 7 and 8 list the top nurturers based on publication count and citations in the time period (1992-2004) respectively.

\subsection{On the selection of $\alpha$}

The figure 3 shows the frequency distributions of the top 1000 nurtureship values on a logarithmic scale for varying $\alpha,\{0,0.25,0.5,1,2\}$. The distribution of the nurtureship values is according to the power law, for all these values of $\alpha$.

In the Nurturer-Finder heuristic, the appropriation of tributes is biased, based on the nurtureship values of associates. This way, people with higher nurtureship values are said to have a greater nurturing influence than the others. $\alpha$ controls the extent to which this biasing happens. Larger values of $\alpha$ will make the "bigger" nurturers get a bigger share of tribute each time, 


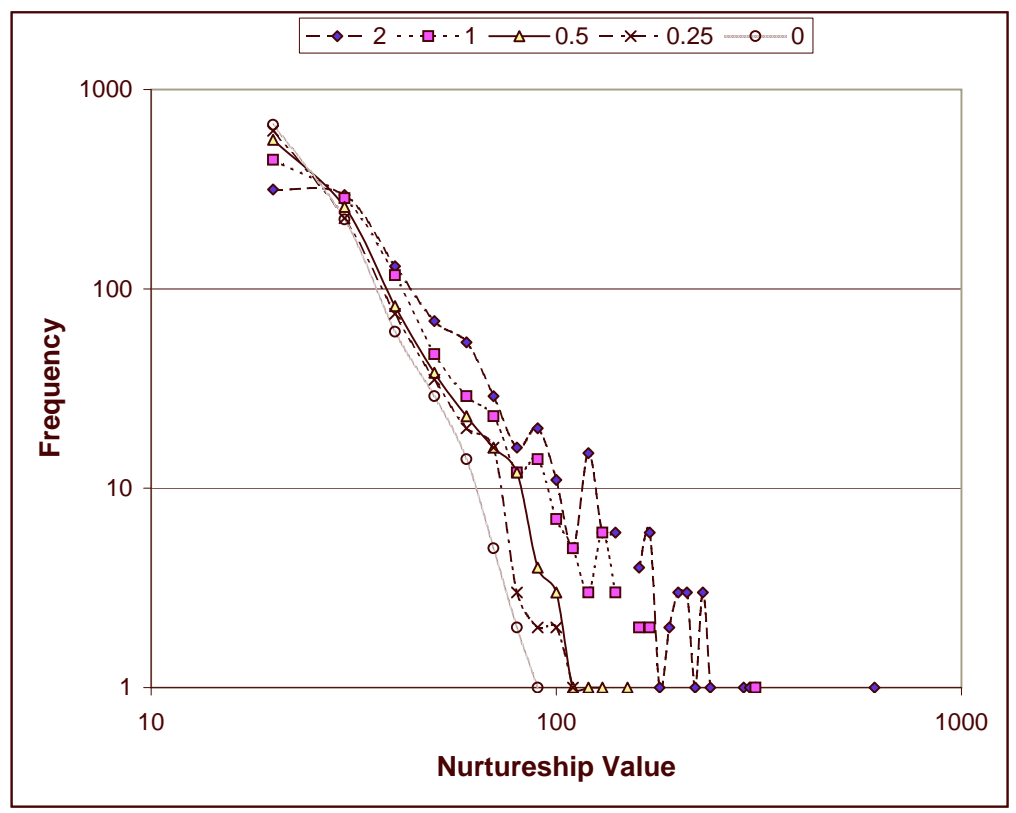

Figure 3: Nurtureship frequency distributions with varying $\alpha$

at the cost of the smaller nurturers. At the same time, if $\alpha$ is 0 , then there is no biasing and tributes are appropriated solely based on the strength of early association. More people get good nurtureship values this way. The frequency distribution for $\alpha=2$ is skewed to the right. This stretch is fuelled by decreased values of nurtureship among the rest of the people, more so among the people who have small nurtureship values.

The $\alpha$ was chosen as 0.5 based on trial and error to engineer semantically acceptable results in some subsets of the database.

\section{Discussion on related work}

Barabasi et. al in [7] show the existence of preferential attachment during addition of new nodes into the collaboration network.

"For a new author, that appears for the first time on a publication, preferential attachment has a simple meaning: it is more likely that the first paper will be co-authored with somebody that already has a large number of co-authors (links) than with somebody less connected. As a result "old" authors with more links will increase their number of co-authors at a higher rate than those with fewer links." 
Does this imply that the best nurturers are simply the best collaborators? When Barabasi et. al. consider the addition of new nodes, they do not track the longetivity and success achieved by that new node in the collaboration network. While good collaborators may be the context for addition of newer nodes, they need not be contexts where people who perform well in the long term may be added. To answer this, a new set of experiments were conducted to identify the best collaborators. Barabasi's experiments consider only the degree of a node to qualify the best collaborators. Here, the best collaborators were said to be those who collaborated with other best collaborators, and had many instances of the same. Thus, it is a weighted sum of the associations had with other good collaborators. This is similar to page rank computation [8], although the weights were computed iteratively year by year. It also differed from the nurturer-finder in that, there was no consideration for earliness, and post-associative significance.

The rankings for top collaborators showed changes when compared to the top nurturers, although the correlation with top collaborators was better than the correlation with the top authors. This suggests that the trait of nurturing is perhaps in some way related to the trait of collaborating. Looking at this the other way, it could also indicate that young people, the new entrants in the network have a preference for good collaborators. Good collaborators typically have good social networks which come in handy for the new.

In continuation to the experiments reported in the paper, the weighted tribute graph formed among the authors can be analysed for transitivity and neighborhoods to discover regions that have nurtured the most people. It is useful to mention [9], where Newman evaluates several social network measures on scientific coauthorship networks. The connectedness of a scientist is measured based on his reachability on a weighted collaboration graph.

The above mentioned references and [10] can be classified as means to infer different roles played by people in collaboration networks. The current work on nurturers can also be grouped alongside.

\section{Conclusion}

The paper presents a new heuristic based on paying tributes for post-associative success, to mine for nurturers in collaboration networks, and uses the same to find the best nurturers in computer science research through parameterizable success measures. Certain boundary conditions due to instant success in some significance measures are carefully handled using the measure of tribute dominance. A way to slice the calculation for a period of time is also presented. 


\section{References}

[1] USNews, http://www.usnews.com

[2] DBLP, http://www.informatik.uni-trier.de/ ley/db/

[3] ISIHighlyCited, http://www.isihighlycited.com

[4] Most cited authors in Computer Science, http://citeseer.ist.psu. edu/mostcited.html

[5] Erdos Number Project, http://www. oakland.edu/enp/

[6] DBL Browser, http://dbis.uni-trier.de/DBL-Browser/

[7] A. L. Barabasi, H. Jeong, Z. Neda, E. Ravasz, A. Schubert, and T. Vicsek. Evolution of the social network of scientific collaboration. Physica A, 311(3-4):590-614, 2002.

[8] S. Brin, L. Page, R. Motwani, and T. Winograd. The page rank citation ranking: Bringing orer to the web. Tech. Rep. 1999-66, Stanford Digital Libraries Working Paper, 1999, http://dbpubs.stanford.edu:8090/ pub/1999-66.

[9] M. E. J. Newman. Who is the best connected scientist? a study of scientific coauthorship networks. Physics Review, E64, 2001

[10] J. Kleinberg. Authoritative sources in a hyperlinked environment. Proc. 9th ACM-SIAM Symposium on Discrete Algorithms, 1998. 


\begin{tabular}{|c|c|c|}
\hline$\overline{R a n k}$ & $\begin{array}{l}\text { Nurturer } \\
\text { Nurtured }\end{array}$ & Value \\
\hline \multirow[t]{9}{*}{8} & C. V. Ramamoorthy & 88 \\
\hline & Benjamin W. Wah & 11 \\
\hline & Vijay K. Garg & 9 \\
\hline & K. Mani Chandy & 9 \\
\hline & Jaideep Srivastava & 9 \\
\hline & K. H. Kim & 8 \\
\hline & Shashi Shekhar & 7 \\
\hline & Wei-Tek Tsai & 5 \\
\hline & Atul Prakash & 5 \\
\hline \multirow[t]{6}{*}{9} & Zvi Galil & 83 \\
\hline & Moti Yung & 10 \\
\hline & David Eppstein & 7 \\
\hline & Kunsoo Park & 7 \\
\hline & Nimrod Megiddo & 6 \\
\hline & Dany Breslauer & 5 \\
\hline \multirow[t]{5}{*}{10} & Christos H. Papadimitriou & 81 \\
\hline & Joseph S. B. Mitchell & 10 \\
\hline & Paris C. Kanellakis & 6 \\
\hline & John N. Tsitsiklis & 5 \\
\hline & Mihalis Yannakakis & 5 \\
\hline \multirow[t]{6}{*}{11} & Ronald L. Rivest & 80 \\
\hline & Robert E. Schapire & 10 \\
\hline & Avrim Blum & 9 \\
\hline & Benny Chor & 5 \\
\hline & Jon Doyle & 5 \\
\hline & Sally A. Goldman & 5 \\
\hline \multirow[t]{4}{*}{12} & Kurt Mehlhorn & 78 \\
\hline & Michael Kaufmann & 11 \\
\hline & Majid Sarrafzadeh & 6 \\
\hline & Norbert Blum & 5 \\
\hline \multirow[t]{5}{*}{$\overline{13}$} & John Mylopoulos & $\overline{77}$ \\
\hline & James P. Delgrande & 10 \\
\hline & Hector J. Levesque & 7 \\
\hline & Nick Roussopoulos & 6 \\
\hline & Alexander Borgida & 5 \\
\hline \multirow[t]{5}{*}{14} & Amir Pnueli & 76 \\
\hline & Dennis Shasha & 9 \\
\hline & David Harel & 5 \\
\hline & Doron Peled & 5 \\
\hline & Oded Maler & 5 \\
\hline \multirow[t]{3}{*}{15} & Grzegorz Rozenberg & 75 \\
\hline & Dirk Vermeir & 7 \\
\hline & Robert Meersman & 6 \\
\hline \multirow[t]{4}{*}{16} & Richard J. Lipton & 75 \\
\hline & Dan Boneh & 8 \\
\hline & Lawrence Snyder & 7 \\
\hline & David P. Dobkin & 5 \\
\hline \multirow[t]{5}{*}{17} & John H. Reif & 74 \\
\hline & Paul G. Spirakis & 17 \\
\hline & Sanguthevar Rajasekaran & 8 \\
\hline & Philip N. Klein & 7 \\
\hline & Sandeep Sen & 6 \\
\hline
\end{tabular}

Table 3: Publication Count: Top nurturers and their nurtured (contd) 


\begin{tabular}{|c|c|c|c|c|}
\hline \multirow[t]{2}{*}{ Rank } & \multicolumn{2}{|l|}{ Top Authors } & \multicolumn{2}{|c|}{ Top Nurturers - Citations } \\
\hline & Name & Value & Name & Value \\
\hline 1 & Jeffrey D. Ullman & 2003.03 & Michael Stonebraker & 938.33 \\
\hline 2 & E. F. Codd & 1448.00 & Jeffrey D. Ullman & 697.26 \\
\hline 3 & Michael Stonebraker & 1292.94 & Catriel Beeri & 547.26 \\
\hline 4 & Jim Gray & 826.00 & David J. DeWitt & 515.27 \\
\hline 5 & Philip A. Bernstein & 781.27 & Philip A. Bernstein & 498.18 \\
\hline 6 & David J. DeWitt & 762.07 & Yehoshua Sagiv & 296.82 \\
\hline 7 & Peter P. Chen & 733.83 & David Maier & 270.27 \\
\hline 8 & Serge Abiteboul & 722.28 & Nathan Goodman & 266.62 \\
\hline 9 & David Maier & 701.49 & Michael J. Carey & 191.56 \\
\hline 10 & Won Kim & 623.57 & Gio Wiederhold & 190.33 \\
\hline 11 & Yehoshua Sagiv & 565.92 & Rakesh Agrawal & 175.84 \\
\hline 12 & Hector Garcia-Molina & 549.05 & Dennis Tsichritzis & 166.20 \\
\hline 13 & Catriel Beeri & 547.55 & Raymond A. Lorie & 163.13 \\
\hline 14 & Nathan Goodman & 517.61 & Christos H. Papadimitriou & 159.81 \\
\hline 15 & Ronald Fagin & 507.51 & Eugene Wong & 155.88 \\
\hline 16 & Umeshwar Dayal & 503.76 & Georges Gardarin & 149.22 \\
\hline 17 & Rakesh Agrawal & 503.16 & Franois Bancilhon & 144.55 \\
\hline 18 & Richard Hull & 486.42 & Bruce G. Lindsay & 138.07 \\
\hline 19 & Michael J. Carey & 471.13 & Michael Hammer & 134.55 \\
\hline 20 & Moshe Y. Vardi & 461.31 & Serge Abiteboul & 132.92 \\
\hline 21 & Carlo Zaniolo & 449.46 & Donald D. Chamberlin & 130.38 \\
\hline 22 & Franois Bancilhon & 443.54 & Stefano Ceri & 116.64 \\
\hline 23 & Raghu Ramakrishnan & 430.50 & Alberto O. Mendelzon & 114.17 \\
\hline 24 & Christos Faloutsos & 400.79 & Dennis McLeod & 113.14 \\
\hline 25 & Jennifer Widom & 390.76 & Timos K. Sellis & 112.83 \\
\hline 26 & Donald E. Knuth & 383.50 & Joachim W. Schmidt & 107.43 \\
\hline 27 & Goetz Graefe & 382.68 & Morton M. Astrahan & 105.91 \\
\hline 28 & C. J. Date & 378.00 & Abraham Silberschatz & 104.22 \\
\hline 29 & Raymond A. Lorie & 373.87 & Ronald Fagin & 102.86 \\
\hline 30 & Richard T. Snodgrass & 366.00 & Raghu Ramakrishnan & 100.57 \\
\hline 31 & Shamkant B. Navathe & 355.71 & Hans-Jrg Schek & 100.52 \\
\hline 32 & Patrick Valduriez & 350.44 & Mihalis Yannakakis & 92.69 \\
\hline 33 & Stefano Ceri & 345.61 & Nick Roussopoulos & 92.34 \\
\hline 34 & Yannis E. Ioannidis & 342.50 & Umeshwar Dayal & 92.09 \\
\hline 35 & Christos H. Papadimitriou & 341.48 & Kapali P. Eswaran & 88.79 \\
\hline 36 & S. Bing Yao & 339.25 & James P. Fry & 87.52 \\
\hline 37 & Nick Roussopoulos & 338.67 & Peter Buneman & 85.93 \\
\hline 38 & Per-ke Larson & 331.79 & Shamkant B. Navathe & 84.93 \\
\hline 39 & H. V. Jagadish & 328.92 & Hector Garcia-Molina & 84.53 \\
\hline 40 & C. Mohan & 319.29 & Moshe Y. Vardi & 82.77 \\
\hline 41 & Antonin Guttman & 315.63 & Clement T. Yu & 79.20 \\
\hline 42 & Eugene Wong & 314.22 & Alfred V. Aho & 74.80 \\
\hline 43 & Jeffrey F. Naughton & 313.76 & Frank Wm. Tompa & 73.95 \\
\hline 44 & David W. Shipman & 310.67 & Theo Hrder & 72.58 \\
\hline 45 & Alberto O. Mendelzon & 308.98 & Yannis E. Ioannidis & 72.09 \\
\hline 46 & Gio Wiederhold & 308.89 & Carlo Batini & 71.31 \\
\hline 47 & Abraham Silberschatz & 298.96 & Jim Gray & 71.09 \\
\hline 48 & Timos K. Sellis & 288.60 & George P. Copeland & 70.67 \\
\hline 49 & Arie Shoshani & 286.18 & Haran Boral & 70.46 \\
\hline 50 & Tomasz Imielinski & 282.59 & Paris C. Kanellakis & 68.30 \\
\hline
\end{tabular}

Table 4: Top 50 authors and nurturers based on citations 


\begin{tabular}{|c|c|c|}
\hline Rank & $\begin{array}{l}\text { Nurturer } \\
\text { Nurtured }\end{array}$ & Value \\
\hline \multirow[t]{17}{*}{1} & Michael Stonebraker & 938 \\
\hline & Antonin Guttman & 163 \\
\hline & Michael J. Carey & 126 \\
\hline & Timos K. Sellis & 101 \\
\hline & Eric N. Hanson & 78 \\
\hline & Yannis E. Ioannidis & 75 \\
\hline & Leonard D. Shapiro & 58 \\
\hline & Joseph M. Hellerstein & 36 \\
\hline & David J. DeWitt & 29 \\
\hline & Lawrence A. Rowe & 29 \\
\hline & Eugene Wong & 28 \\
\hline & Sunita Sarawagi & 21 \\
\hline & Daniel R. Ries & 17 \\
\hline & Frank Olken & 14 \\
\hline & Randy H. Katz & 13 \\
\hline & Erich J. Neuhold & 13 \\
\hline & John K. Ousterhout & 12 \\
\hline \multirow[t]{16}{*}{2} & Jeffrey D. Ullman & 697 \\
\hline & Yehoshua Sagiv & 89 \\
\hline & David Maier & 73 \\
\hline & Alberto O. Mendelzon & 66 \\
\hline & Catriel Beeri & 64 \\
\hline & Ashish Gupta & 45 \\
\hline & Allen Van Gelder & 41 \\
\hline & Gabriel M. Kuper & 34 \\
\hline & Yannis Papakonstantinou & 29 \\
\hline & Fereidoon Sadri & 19 \\
\hline & Arthur M. Keller & 18 \\
\hline & Moshe Y. Vardi & 17 \\
\hline & M. R. Garey & 17 \\
\hline & Anand Rajaraman & 14 \\
\hline & Dallan Quass & 13 \\
\hline & Franois Bancilhon & 11 \\
\hline \multirow[t]{14}{*}{3} & Catriel Beeri & 547 \\
\hline & Moshe Y. Vardi & 99 \\
\hline & Raghu Ramakrishnan & 72 \\
\hline & Michael Kifer & 68 \\
\hline & Henry F. Korth & 43 \\
\hline & Tova Milo & 33 \\
\hline & Philip A. Bernstein & 24 \\
\hline & Serge Abiteboul & 23 \\
\hline & Jeffrey D. Ullman & 23 \\
\hline & Nathan Goodman & 17 \\
\hline & Gerhard Weikum & 16 \\
\hline & Ron Obermarck & 11 \\
\hline & David Maier & 11 \\
\hline & Alberto O. Mendelzon & 11 \\
\hline \multirow[t]{7}{*}{4} & David J. DeWitt & 515 \\
\hline & Rakesh Agrawal & 118 \\
\hline & Goetz Graefe & 90 \\
\hline & Haran Boral & 33 \\
\hline & Hong-Tai Chou & 32 \\
\hline & Shahram Ghandeharizadeh & 19 \\
\hline & Jim Gray & 18 \\
\hline
\end{tabular}

Table 5: Citations: Top nurturers and their nurtured 


\begin{tabular}{|c|c|c|}
\hline \multirow[t]{6}{*}{ Rank } & $\begin{array}{l}\text { Nurturer } \\
\text { Nurtured }\end{array}$ & Value \\
\hline & Michael J. Carey & 18 \\
\hline & M. Muralikrishna & 18 \\
\hline & Donovan A. Schneider & 17 \\
\hline & Eugene J. Shekita & 15 \\
\hline & Dina Bitton & 12 \\
\hline \multirow[t]{10}{*}{5} & Philip A. Bernstein & 498 \\
\hline & Umeshwar Dayal & 148 \\
\hline & David W. Shipman & 82 \\
\hline & Nathan Goodman & 54 \\
\hline & Catriel Beeri & 46 \\
\hline & Marco A. Casanova & 35 \\
\hline & Harry K. T. Wong & 35 \\
\hline & Christos H. Papadimitriou & 29 \\
\hline & Barbara T. Blaustein & 11 \\
\hline & John Mylopoulos & 11 \\
\hline \multirow[t]{8}{*}{6} & Yehoshua Sagiv & 296 \\
\hline & Mihalis Yannakakis & 48 \\
\hline & Alon Y. Levy & 47 \\
\hline & David Maier & 41 \\
\hline & Jeffrey D. Ullman & 28 \\
\hline & Anand Rajaraman & 20 \\
\hline & Alberto O. Mendelzon & 19 \\
\hline & Jeffrey F. Naughton & 17 \\
\hline \multirow[t]{10}{*}{7} & David Maier & 270 \\
\hline & David Scott Warren & 44 \\
\hline & George P. Copeland & 40 \\
\hline & Jeffrey D. Ullman & 24 \\
\hline & Alberto O. Mendelzon & 19 \\
\hline & Goetz Graefe & 19 \\
\hline & Jacob Stein & 15 \\
\hline & William J. McKenna & 14 \\
\hline & Albert Croker & 13 \\
\hline & Yehoshua Sagiv & 13 \\
\hline \multirow[t]{9}{*}{8} & Nathan Goodman & 266 \\
\hline & Oded Shmueli & 70 \\
\hline & Catriel Beeri & 31 \\
\hline & Christos H. Papadimitriou & 29 \\
\hline & Johann Christoph Freytag & 28 \\
\hline & Dennis Shasha & 22 \\
\hline & Umeshwar Dayal & 21 \\
\hline & Randy H. Katz & 19 \\
\hline & Philip A. Bernstein & 15 \\
\hline \multirow[t]{6}{*}{9} & Michael J. Carey & 191 \\
\hline & Rakesh Agrawal & 48 \\
\hline & Hongjun Lu & 31 \\
\hline & Miron Livny & 22 \\
\hline & Michael J. Franklin & 19 \\
\hline & David J. DeWitt & 11 \\
\hline \multirow[t]{6}{*}{10} & Gio Wiederhold & 190 \\
\hline & Ramez Elmasri & 52 \\
\hline & Xiaolei Qian & 26 \\
\hline & Hector Garcia-Molina & 24 \\
\hline & Stefano Ceri & 18 \\
\hline & Domenico Sacc & 11 \\
\hline
\end{tabular}

Table 6: Citations: Top nurturers and their nurtured (contd) 


\begin{tabular}{|c|c|c|}
\hline \multirow[t]{2}{*}{ Rank } & \multicolumn{2}{|c|}{ Top Nurturers for Publication Count since 1992} \\
\hline & Name & Value \\
\hline 1 & Micha Sharir & 44.02 \\
\hline 2 & Alberto L. Sangiovanni-Vincentelli & 38.83 \\
\hline 3 & Hector Garcia-Molina & 34.41 \\
\hline 4 & Ugo Montanari & 34.20 \\
\hline 5 & Kang G. Shin & 33.15 \\
\hline 6 & Avi Wigderson & 31.71 \\
\hline 7 & Stefano Ceri & 30.76 \\
\hline 8 & Elisa Bertino & 30.32 \\
\hline 9 & Fausto Giunchiglia & 30.27 \\
\hline 10 & Hongjun Lu & 29.79 \\
\hline 11 & Michael Stonebraker & 29.02 \\
\hline 12 & Oded Goldreich & 28.36 \\
\hline 13 & Jiawei Han & 28.20 \\
\hline 14 & Philip S. Yu & 27.21 \\
\hline 15 & Noga Alon & 27.04 \\
\hline 16 & Donald F. Towsley & 26.76 \\
\hline 17 & Joseph Y. Halpern & 26.46 \\
\hline 18 & Thomas S. Huang & 25.68 \\
\hline 19 & Leonidas J. Guibas & 25.63 \\
\hline 20 & Satish K. Tripathi & 25.43 \\
\hline 21 & Sushil Jajodia & 25.22 \\
\hline 22 & Jeffrey D. Ullman & 24.99 \\
\hline 23 & Richard R. Muntz & 24.65 \\
\hline 24 & Randy H. Katz & 24.45 \\
\hline 25 & Alex Pentland & 24.38 \\
\hline 26 & Abraham Silberschatz & 24.24 \\
\hline 27 & Edmund M. Clarke & 23.36 \\
\hline 28 & Friedhelm Meyer auf der Heide & 23.34 \\
\hline 29 & Richard M. Karp & 23.07 \\
\hline 30 & Moti Yung & 22.98 \\
\hline 31 & Roberto Gorrieri & 22.88 \\
\hline 32 & John Mylopoulos & 22.61 \\
\hline 33 & Zohar Manna & 22.27 \\
\hline 34 & Amir Pnueli & 22.21 \\
\hline 35 & V. S. Subrahmanian & 22.06 \\
\hline 36 & Richard J. Lipton & 22.00 \\
\hline 37 & Krithi Ramamritham & 21.99 \\
\hline 38 & Ricardo A. Baeza-Yates & 21.90 \\
\hline 39 & Josef Kittler & 21.86 \\
\hline 40 & Christos Faloutsos & 21.35 \\
\hline 41 & Rajeev Motwani & 21.28 \\
\hline 42 & Timos K. Sellis & 21.28 \\
\hline 43 & Kishor S. Trivedi & 21.24 \\
\hline 44 & Giorgio Levi & 21.23 \\
\hline 45 & David E. Goldberg & 21.05 \\
\hline 46 & Paul G. Spirakis & 20.91 \\
\hline 47 & Jack Dongarra & 20.78 \\
\hline 48 & Mukesh Singhal & 20.53 \\
\hline 49 & Robert Endre Tarjan & 20.38 \\
\hline 50 & Georg Gottlob & 20.34 \\
\hline
\end{tabular}

Table 7: Top 50 nurturers based on publication count since 1992 


\begin{tabular}{|c|c|c|}
\hline \multirow[t]{2}{*}{ Rank } & \multicolumn{2}{|c|}{ Top Nurturers for Citations since 1992} \\
\hline & Name & Value \\
\hline 1 & Jeffrey D. Ullman & 142.00 \\
\hline 2 & Yehoshua Sagiv & 100.92 \\
\hline 3 & Michael Stonebraker & 77.20 \\
\hline 4 & David J. DeWitt & 54.96 \\
\hline 5 & Yannis E. Ioannidis & 53.51 \\
\hline 6 & Hector Garcia-Molina & 50.96 \\
\hline 7 & Peter Buneman & 45.02 \\
\hline 8 & Rakesh Agrawal & 34.28 \\
\hline 9 & Raghu Ramakrishnan & 33.90 \\
\hline 10 & Jennifer Widom & 30.96 \\
\hline 11 & Stefano Ceri & 30.84 \\
\hline 12 & Timos K. Sellis & 30.30 \\
\hline 13 & Michael J. Carey & 29.52 \\
\hline 14 & Serge Abiteboul & 26.40 \\
\hline 15 & Philip S. Yu & 25.17 \\
\hline 16 & V. S. Subrahmanian & 24.91 \\
\hline 17 & Ashish Gupta & 24.86 \\
\hline 18 & Moshe Y. Vardi & 24.78 \\
\hline 19 & Catriel Beeri & 24.65 \\
\hline 20 & Abraham Silberschatz & 23.77 \\
\hline 21 & Patrick Valduriez & 22.15 \\
\hline 22 & Christos Faloutsos & 21.91 \\
\hline 23 & Kevin Strehlo & 19.00 \\
\hline 24 & Dennis McLeod & 17.47 \\
\hline 25 & Arun N. Swami & 17.40 \\
\hline 26 & Waqar Hasan & 16.78 \\
\hline 27 & Alfons Kemper & 16.22 \\
\hline 28 & Hamid Pirahesh & 15.74 \\
\hline 29 & Paris C. Kanellakis & 15.36 \\
\hline 30 & Miron Livny & 14.59 \\
\hline 31 & Stanley B. Zdonik & 13.96 \\
\hline 32 & Jeffrey F. Naughton & 13.30 \\
\hline 33 & Vincent Y. Lum & 13.15 \\
\hline 34 & Dallan Quass & 12.91 \\
\hline 35 & Heikki Mannila & 12.48 \\
\hline 36 & Hans-Jrg Schek & 12.23 \\
\hline 37 & Tomasz Imielinski & 12.16 \\
\hline 38 & Paolo Atzeni & 11.84 \\
\hline 39 & Jan Paredaens & 11.81 \\
\hline 40 & Limsoon Wong & 11.65 \\
\hline 41 & Inderpal Singh Mumick & 11.33 \\
\hline 42 & Bruce G. Lindsay & 11.27 \\
\hline 43 & Balakrishna R. Iyer & 10.99 \\
\hline 44 & Raymond T. Ng & 10.89 \\
\hline 45 & Barton P. Miller & 10.88 \\
\hline 46 & H. V. Jagadish & 10.63 \\
\hline 47 & Ming-Syan Chen & 10.59 \\
\hline 48 & A. Inkeri Verkamo & 10.26 \\
\hline 49 & Michel Scholl & 10.25 \\
\hline 50 & Fereidoon Sadri & 10.17 \\
\hline
\end{tabular}

Table 8: Top 50 nurturers based on citations since 1992 